\title{
Editorial
}

\section{Class III antiarrhythmics: put to the SWORD?}

The prediction and prevention of sudden cardiac death remain among the greatest challenges in cardiology. Evidence from attempted cardiopulmonary resuscitation and from fortuitous ambulatory electrocardiographic monitoring at the time of cardiac arrest indicates that ventricular fibrillation, commonly preceded by rapid ventricular tachycardia, is the commonest mode of sudden death. ${ }^{12}$ Although sudden cardiac death may present as the first clinical manifestation of cardiac disease, ${ }^{3}$ in many patients there is a past history of angina, myocardial infarction, or cardiac failure. ${ }^{4}$ Much effort has been devoted to the identification of markers of risk for sudden cardiac death in patients with known heart disease, particularly after myocardial infarction. Early studies identified the independent contribution of frequent ventricular ectopic activity and depressed left ventricular ejection fraction as predictors of sudden death, ${ }^{56}$ while more recent studies have implicated autonomic disturbance as manifest by impaired heart rate variability and depressed baroreflex sensitivity. ${ }^{78}$

\section{Class I agents}

The association between frequent ventricular premature beats or non-sustained ventricular tachycardia on ambulatory monitoring and the subsequent development of ventricular tachycardia or fibrillation led to the hypothesis that suppression of asymptomatic ventricular arrhythmias would reduce the risk of sudden cardiac death in patients after myocardial infarction. This hypothesis was submitted to its most rigorous examination in the Cardiac Arrhythmia Suppression Trials (CAST), ${ }^{910}$ in which the effects of flecainide, encainide, and moracizine were evaluated. The clear identification of an increase in mortality associated with active treatment in these trials has had a profound influence on attitudes to antiarrhythmic drug treatment, particularly regarding the safety of class Ic antiarrhythmic drugs. There was particular evidence of increased mortality in subgroups of patients with more depressed left ventricular ejection fraction, and in those at greater risk of recurrent ischaemic episodes, such as patients with non-Q-wave infarction. ${ }^{11}$ An increase in the incidence of heart failure or of cardiogenic shock after reinfarction suggested that the negative inotropic effects of flecainide and encainide were having an important clinical influence. There was evidence of a worsened prognosis even in patients with well preserved ventricular function, a group in which the mortality while on placebo treatment

Glossary

CASCADE = Cardiac arrest in Seattle: conventional versus amiodarone drug evaluation.

CAST = Cardiac arrhythmia suppression trials.

CHF-STAT = Congestive heart failure survival trial of antiarrhythmic

DIAMOND $=$ Danish investigation of arrhythmia and mortality on dofetilide. GESICA = Gruppo de estudio de la sobrevida en la insuficiencia cardiaca en

SWORD = Survival with oral $d$-sotalol. was significantly lower than expected. Although CAST investigated only three antiarrhythmic drugs, indirect evidence suggests that the excess risk associated with class I antiarrhythmic drugs of other types, such as quinidine, is as great if not greater than those of class Ic agents. ${ }^{12}$

The apparent failure of the approach based on the "ventricular premature beat hypothesis" is evident from the fact that the excess deaths in the CAST trials occurred despite adequate suppression of asymptomatic ventricular arrhythmias. A possible explanation for this paradoxical finding lies in the modification of the class I antiarrhythmic action in the face of increased catecholamine concentrations or acute myocardial ischaemia. The ability of class I drugs to control arrhythmias is diminished in the presence of catecholamines, ${ }^{13}$ while experimental data indicate that acute ischaemia may radically alter the electrophysiological effects of class I agents, by enhancing the degree of sodium channel blockade thus opening the possibility of the production of new areas of slow conduction or unidirectional block which may lead to re-entry arrhythmias. ${ }^{14}$

\section{$\beta$-Adrenoceptor antagonists}

In contrast to the failure of class I agents in preventing sudden death, the alternative approach of suppression of the effects of catecholamines and myocardial ischaemia by the use of $\beta$ adrenergic receptor antagonists has produced clear evidence of a reduction in both myocardial reinfarction and sudden cardiac death in many studies of patients after infarction. ${ }^{15}$ Although clinical trials of $\beta$ adrenergic antagonists have included patients with left ventricular dysfunction whose evidence of cardiac failure is controlled by diuretic treatment, ${ }^{15} 16$ many physicians remain concerned about the safety of prescribing $\beta$ blockers to the patient with severely depressed left ventricular function and frequent ventricular ectopic activity who is at the highest risk of sudden death.

\section{Amiodarone and sotalol}

The evident failure of class I antiarrhythmic agents to prevent sudden death, coupled with the perceived limitation of $\beta$ blockers in the patients at highest risk, has lead to interest in the possible use of class III antiarrhythmic agents. Unlike inhibition of the sodium channel, prolongation of the action potential duration by inhibition of the delayed rectifier current results in a modest positive rather than a negative inotropic action. ${ }^{17}$ Thus the use of class III agents in patients with severe left ventricular dysfunction does not seem to exacerbate cardiac failure. Until recent years, the only agents available with class III antiarrhythmic activity were $d l$-sotalol and amiodarone. Both drugs are complex in their actions, with $d l$-sotalol being a non-selective, competitive $\beta$ adrenergic antagonist and amiodarone having non-competitive anti-sympathetic properties as well as class I and class IV effects.

The effects of $d l$-sotalol on overall mortality in survivors of myocardial infarction was investigated by Julian et al who reported a non-significant $19 \%$ reduction in overall 
mortality. ${ }^{18}$ This result, while not statistically significant, was within the range seen for other $\beta$ blocking agents, but did not suggest that $d l$-sotalol possessed greater abilities to prevent sudden death than conventional $\beta$ blockers. In a population of patients with sustained ventricular tachycardia, $d l$-sotalol was more effective than conventional class I antiarrhythmic drugs in suppressing ventricular ectopic activity and preventing arrhythmia induction during electrophysiological study. ${ }^{19}$ The risk of tachycardia recurrence and of death was lower in the group treated with sotalol rather than with other drugs. However, this was not a randomised comparison of antiarrhythmic drug treatment, and the effect of conventional $\beta$ blockade was not investigated. This omission is important, because an additional recent study suggested that empirical treatment with metoprolol produced equivalent prevention of recurrent ventricular tachyarrhythmias to that achieved with electrophysiologically guided drug treatment. ${ }^{20}$

Despite concerns about non-cardiac toxicity, amiodarone has been investigated as a possible agent for reduction of sudden cardiac death in high risk patients. Two small post-infarction studies have indicated a reduction in mortality on amiodarone treatment ${ }^{212}$ although in the Basel study the benefit seemed to be limited to patients with preserved left ventricular function. ${ }^{23}$ Amiodarone was compared with conventional antiarrhythmic drug treatment in a randomised study performed in survivors of outof-hospital cardiac arrest (CASCADE). ${ }^{24}$ Survival was greater in the amiodarone treated group, but the absence of a placebo group in this study makes it impossible to distinguish between a beneficial effect of amiodarone and an adverse effect of conventional class I drug treatment on survival. In recently published trials of amiodarone in patients in congestive heart failure, a confusing picture has emerged. The GESICA trialists reported a $30 \%$ reduction in all cause mortality, with approximately equal effects on sudden death and death caused by progression of heart failure..$^{25}$ In contrast, the American CHF-STAT study of amiodarone in patients with heart failure of predominantly ischaemic aetiology did not show any beneficial effect. ${ }^{26}$

\section{Selective class III agents}

The recent development of selective class III antiarrhythmic drugs has enabled studies to be performed that can dissociate the effects of lengthening of action potential duration from the antisympathetic effects inherent in treatment with amiodarone or $d l$-sotalol. $d$-Sotalol is the isomer of $d l$-sotalol which contains only one-fourteenth of the $\beta$ blocking property of the racemic mixture. After initially encouraging reports of the ability of $d$-sotalol to prevent the induction of ventricular tachycardia, ${ }^{27}$ the agent was evaluated in a large scale mortality study. The Survival with Oral $d$-Sotalol (SWORD) study was a placebo controlled study comparing the effect of $d$-sotalol $200-400 \mathrm{mg}$ daily with placebo. The patient population comprised survivors of acute myocardial infarction with left ventricular ejection fractions $\leqslant 0.40$, enrolled $6-42$ days after infarction. In addition, patients with established congestive cardiac failure in New York Heart Association classes II and III caused by remote myocardial infarction were recruited. The study was terminated prematurely on the advice of the Data and Safety Monitoring Committee as a result of a significant excess of deaths in the $d$-sotalol treatment arm $(4.6 \% v 2 \cdot 7 \%, p=0.005){ }^{28}$ As had been observed previously in the CAST studies, the survival curves diverged continuously, suggesting that excess risk was present throughout the period of exposure rather than in a brief period after the introduction of the drug. Mortality in the placebo treated group in the SWORD study was lower than predicted, which raises the possibility that treatment with $d$-sotalol in an insufficiently high risk group may have exposed patients to the risk of lethal proarrhythmia while the prospects of significant benefit were low. The notion that $d$-sotalol might be of value in very high risk populations was investigated in a trial comparing $d$-sotalol with amiodarone in patients with recurrent sustained ventricular tachycardia and in a placebo-controlled study of $d$-sotalol in patients with implantable cardioverter-defibrillators. The results of these studies have not yet been published but the manufacturer has terminated further development of $d$-sotalol.

The demise of $d$-sotalol puts in doubt the further development of other selective class III antiarrhythmic drugs. The highly selective agent dofetilide was shown to suppress inducible ventricular tachyarrhythmias, ${ }^{29}$ and is currently the subject of a large scale mortality trial, the DIAMOND study, in Denmark. At the time of writing, this study is still continuing.

The pattern of excess deaths in the SWORD study is uncannily similar to that in CAST, and again raises the possibility that the interaction of a powerful electrophysiological agent with changes in the myocardial electrophysiological substrate caused by catecholamines or ischaemia may turn an effective antiarrhythmic drug into a potentially lethal proarrhythmic agent. It is well established experimentally that the class III activity of $d$-sotalol is abolished during acute myocardial ischaemia, ${ }^{30}$ whereas the effects of class III agents are also attenuated in the presence of catecholamines. ${ }^{31}$ It seems likely that the apparent therapeutic advance brought about by the availability of "pure" class III antiarrhythmic drugs may have been illusory. The future of class III antiarrhythmic treatment, if any, will lie in combinations possessing antiadrenergic properties, such as amiodarone and $d l$-sotalol.

STUART M COBBE

Department of Medical Cardiology,

Royal Infirmary University NHS Trust,

10 Alexandra Parade,

Glasgow G31 2ER

1 Myérburg RJ, Conde CA, Sug RJ, Mayorga-Cortes A, Mallon SM, Sheps DS, et al. Clinical, electrophysiologic and haemodynamic profile of patients resuscitated from prehospital cardiac arrest. $A m \mathcal{F} \mathrm{Med}$ 1980;68:568-76.

2 Bayes de Luna A, Coumel P, Leclercq JF. Ambulatory sudden cardiac death: mechanisms of production of fatal arrhythmia on the basis of data from 157 cases. Am Heart $\mathcal{f} 1989 ; 117: 151-9$.

3 Kannel WB, Schatzkin A. Sudden death: lessons from subsets in population studies. F Am Coll Cardiol 1985;5(suppl):141B-9B.

4 Goldstein S, Medendorp SV, Landis JR, Wolfe RA, Leighton R, Ritter G, et al. Analysis of cardiac symptoms preceding cardiac arrest. Am $\mathcal{F}$ Cardiol 1986;58:1195-8.

5 Bigger JT Jr, Fleiss JL, Kleiger R, Miller JP, Rolnitsky LM and The Multicenter Post-Infarction Group. The relationship between ventricular arrhythmias, left ventricular dysfunction and mortality in the 2 years after myocardial infarction. Circulation 1984;69:250-8.

6 Mukharji J, Rude Re, Poole WK, Gustafson N, Thomas LJ, Strauss HW, et al. Risk factors for sudden death following acute myocardial infarction al. Risk factors for sudden death following acute
(two year follow up). Am $₹$ Cardiol 1984;54:31-46.

7 Kleiger RE, Miller JD, Bigger JT, Moss AJ and the Multicenter Post-infarction Research Group. Decreased heart rate variability and its association tion Research Group. Decreased heart rate variability and its association with increased mo

8 La Rovere MT, Specchia G, Mortara A, Schwartz PJ. Baroreflex sensitivity, clinical correlates and cardiovascular mortality among patients with a firs myocardial infarction. A prospective study. Circulation 1988;78:816-24.

9 Echt DS, Liebson PR, Mitchell LB, Peters RW, Obias-Manno D, Barker $\mathrm{AH}$, et al. Mortality and morbidity in patients receiving encainide, flecainide or placebo. The Cardiac Arrhythmia Suppression Trial. $N$ Engl $\mathcal{J}$ Med 1991;324:781-7

10 The Cardiac Arrhythmia Suppression Trial II Investigators. Effect of the antiarrhythmic agent moricizine on survival after myocardial infarction. $N$ Engl ₹ Med 1992;327:227-33.

11 Akiyama T, Pawitan Y, Greenberg H, Kuo CS, Reynolds-Haertle RA Increased risk of death and cardiac arrest from encainide and flecainide in patients after non-Q-wave acute myocardial infarction in the Cardiac Arrhythmia Suppression Trial. CAST Investigators. Am $\mathcal{f}$ Cardiol 1991; 68:1551-5.

12 Morganroth J, Goin JE. Quinidine-related mortality in the short-tomedium-term treatment of ventricular arrhythmias. A meta-analysis. Circulation 1991;84:1977-83.

13 Jazayeri MR, Van Wyhe G, Avitall B, McKinnie J, Tchou P, Akhtar M. Isoproterenol reversal of antiarrhythmic effects in patients with inducible sustained ventricular tachyarrhythmias. $\mathcal{f} \mathrm{Am}$ Coll Cardiol 1989;14: 705-11. 
14 El-Sherif $N$, Scherlag BJ, Lazzara $R$, Hope $R R$. Reentrant ventricular arrhythmias in the late myocardial infarction period. 4 . Mechanism of action of lidocaine Circulation 1977; 56:395-402.

15 Yusuf S, Peto R, Lewis J, Collins R, Sleight P. Beta blockade during and after myocardial infarction: an overview of the randomized trials. Prog Cardiovasc Dis 1985;27:335-71.

16 Beta-blocker Heart Attack Trial Research Group. A randomized trial of propranolol in patients with acute myocardial infarction. $¥ A M A 1982 ; 247$ 1707-14.

17 Tande PM, Refsum H. Class III antiarrhythmic action linked with positive inotropy: effects of the $d$ - and $l$-isomer of sotalol on isolated rat atria at threshold and suprathreshold stimulation. Pharmacol Toxicol 1988;61: $272-7$.

18 Julian DG, Prescott RJ, Jackson FS, Szekely P. Controlled trial of sotalol for one year after myocardial infarction. Lancet 1982;i:1142-7.

19 Mason JW for the Electrophysiologic Study versus Electrocardiographic Monitoring Investigators. A comparison of seven antiarrhythmic drugs in patients with ventricular tachyarrhythmias. $N$ Engl f Med 1993;329: comparison of electrophysiologically guided antiarrhythmic drug therapy with beta-blocker therapy in patients with symptomatic, sustained ventricular tachyarrhythmias. N Engl f Med 1992;327:987-92.

21 Burkart F, Pfisterer M, Kiowski W, Follath F, Burckhardt D. Effect of antiarrhythmic therapy on mortality in survivors of myocardial infarction with asymptomatic complex ventricular arrhythmias: Basel Antiarrhythmic Study of Infarct Survival (BASIS). F Am Coll Cardiol 1990;16: 1711-8.

22 Ceremuzynski L, Kleczar E, Krzeminska-Pakula M, Kuch J, Nartowicz E, Smielak-Korombel $\mathrm{J}$, et al. Effect of amiodarone on mortality after myocardial infarction: a double-blind, placebo-controlled pilot study.
7 Am Coll Cardiol 1992;20:1056-62.

23 Pfisterer M, Kiowski W, Burckhardt D, Follath F, Burkart F. Beneficial effect of amiodarone on cardiac mortality in patients with asymptomatic complex ventricular arrhythmias after acute myocardial infarction and preserved but not impaired left ventricular function. Am $f$ Cardiol 1992; 69:1399-402

24 The CASCADE Investigators. Randomized antiarrhythmic drug therapy in survivors of cardiac arrest (the CASCADE study). $\mathcal{F} \mathrm{Am}$ Coll Cardiol $1993 ; 72 ; 280-7$.

25 Doval HC, Nul DR, Grancelli HD, Perrone SV, Bortman GR, Curiel, R for GESICA. Randomised trial of low-dose amiodarone in severe congestive heart failure. Lancet 1994;344:493-8.

26 Singh SN, Fletcher RD, Fisher SG, Lewis HD, Deedwania PC, Massie $B M$, et al Results of the Congestive Heart Failure Survival Trial of Antiarrhythmic Therapy. Circulation 1994;90(suppl I):I-546.

27 Brachmann J, Schoels W, Beyer T, Hibel T, Enders B, Versheuren J, et al. Acute antiarrhythmic effects of $d$-sotalol in patients with sustained ventricular tachyarrhythmias. Circulation 1993;88(suppl I):I-445.

28 Waldo AL, Camm AJ, de Ruyter H, Friedman PL, MacNeil DJ, Pitt B, al. Preliminary mortality results from the Survival With Oral D-Sotalol al. Preliminary mortality results from the Survival With

29 Thomsen P, Bashir Y, Kingma J, Moller M, Camm A, Butrous G, et al. Dofetilide in the treatment of sustained monomorphic ventricular tachycardia [abstr]. Eur Hear $₹$ 1992;13:304.

30 Hicks MN, Cobbe SM. Attenuation of the rise in extracellular potassium concentration during myocardial ischaemia by $d l$-sotalol and $d$-sotalol. Cardiovasc Res 1990;24:404-10.

31 Sager PT, Follmer C, Uppal P, Pruitt C, Godfrey R. The effects of betaadrenergic stimulation on the frequency-dependent electrophysiologic actions of amiodarone and sematilide in humans. Circulation 1994;90 1811-9. 